\title{
Forum
}

\section{Schwerpunktthema: Europa am Scheideweg? Zustand und Zukunft der Europäischen Union}

Der Zustand der Europäischen Union scheint Besorgnis erregend: die Schuldenkrise einiger Euro-Staaten und in deren Folge die Gefahr des Zusammenbruchs der Gemeinschaftswährung, das Tauziehen um Finanzhilfen, der wachsende Zuspruch populistischer und europaskeptischer Parteien, die Wiedereinführung von Grenzkontrollen in einigen Schengenstaaten, überhaupt die kaum zu übersehenden Re-Nationalisierungstendenzen. Die Liste ließe sich fortsetzen. Und wo man auch hinblickt: In unschöner Regelmäßigkeit tauchen neue Brandherde auf, die es durch die Politik zu löschen gilt. Doch wo entschlossenes Handeln und Einigkeit vonnöten wären, herrschen Kakophonie und Zaudern unter den politischen Akteuren. Der Vorrat an Gemeinsamkeiten scheint zu schwinden, die gemeinsame Basis wird brüchig. Die gemeinsame europäische Idee, die auf mittlere Sicht als Leitbild den Kurs für eine Erweiterung und Vertiefung Europas vorgeben und neue Energien freisetzen könnte, ist nicht auszumachen. Auf der anderen Seite betonen die EU-Befürworter weiterhin die Notwendigkeit und Alternativlosigkeit der europäischen Integration und des Euro. Es wird Sondergipfel um Sondergipfel abgehalten, es werden immer wieder neue finanzielle Hilfspakete geschnürt und Rettungsschirme gespannt, um den „Tanker Europa“ wieder flott zu machen.

Vor diesem Hintergrund nimmt das Forum unter der Fragestellung „Europa am Scheideweg?" den Zustand und die Zukunft der Europäischen Union in den Blick. Dabei widmet sich Werner Weidenfeld in seinem Essay der Suche nach einer gemeinsamen europäischen Identität und stellt die Frage der Revitalisierung derselben. Frank Decker beleuchtet den Stand und mögliche Perspektiven des europäischen Integrationsprojektes. Gisela Müller-Brandeck-Bocquet schließlich unterzieht die Außen- und Sicherheitspolitik der Europäischen Union einer kritischen Bestandsaufnahme. 